\title{
Egocentric Space
}

\section{Introduction: visual space and bodily activity}

There are clearly a number of close connections between visual space, that is, space as presented in visual perception, and the capacity for bodily activity. ${ }^{1}$ It is commonplace that what we see at any one time is partly determined by our active bodily activity; in order to see what is going on to my left, I turn my head. Similarly, it is certainly intuitively plausible that my bodily activities are, in part, guided by the visual experience of the space around me; my reaching to the right to pick up my coffee cup is, in part, guided by a visual experience in which the cup appears to the right. ${ }^{2}$ As stated, these commonplace connections might be taken to be very general empirical claims, that the connection between visual space and bodily activity is contingent, a posteriori, but not constitutive of either phenomenon. However, a number of philosophers have claimed that there is, in fact, a constitutive connection between visual space and bodily activity. The claim is that certain features of visual space are, in part, constituted by their relation to the capacity for bodily activity. Variations on such a claim can be found in the work of, amongst others, Maurice Merleau-Ponty $(1945)^{3}$, Charles Taylor (1978), Gareth Evans (1982), Bill Brewer(1992), John Campbell (1993), Quassim Cassam (2002), Susan Hurley (1998), Rick Grush (1998), Jeff Malpas (1999), Pete Mandik (1999) and Alva Noë (2004).

One way of defending this claim begins from the idea that that space as it is presented in visual experience is perspectival, or oriented, or egocentric. As a rough, first approximation, this is the fact that perception is from somewhere, visual experience presents the world from a particular point of view. We can show, so it is claimed, that there is a constitutive connection between bodily activity and the orientation of the visual field. ${ }^{4} \mathrm{~A}$ helpful initial gloss on what this orientation amounts to is provided by Charles Taylor, who claims that, "[o]ur perceptual field has an orientational structure, a foreground and a background, an up and down. And it must have; that is, it

\footnotetext{
${ }^{1}$ I use 'activity' rather than 'action' to avoid any suggested relation to intention. Activity, as I understand it, includes both intentional acts and sub-intentional acts (in O'Shaughnessy's (1980, vol.2, ch.10) sense). Bodily activity is a sub species of bodily movement, which also includes movements in which the subject is passive. I sometimes drop 'bodily', but it is to be understood throughout, i.e. mental actions and activities, such as attending, are not included.

${ }^{2}$ For a discussion of whether this intuitively plausible claim is true, see (Campbell 2002, ch.3).

${ }^{3}$ I use the 2012 Landes translation of Phénoménologie de la perception, and page references are to that. Where the translation differs in a significant way from Smith's 1962 translation, I note the fact.

${ }^{4}$ Use of the phrase 'visual field' should not be thought to imply a sense-data theory of visual perception. See (Martin 1992). As I understand it, it is equivalent to what Merleau-Ponty calls 'the spectacle', the visual element of the 'phenomenal field', see (Merleau-Ponty 1945, 52-65).
} 
can't lose this structure without ceasing to be a perceptual field in the full sense, i.e. our opening onto the world." (Taylor 1978, 254). ${ }^{5}$ This orientational structure, it is claimed, is explained by the constitutive connection between visual space and bodily activity. ${ }^{6}$ One version of this claim would be that, say, for something to be presented as in the left of the visual field is simply it to be presented in such a way that it seems that to reach/point to it one must reach/point to the left (Noë 2004, 87-8). I will call the generic dependency claim Act-Space:

Act-Space: The orientation of visual space-visually presented direction-is partly constituted by its relation to bodily activity.

This claim is most prominent in Merleau-Ponty's influential work on the perception of space, in particular his Phenomenology of Perception. It has roots, however, in a short pre-critical work of Kant's (1768). ${ }^{7}$ To get some context, it is instructive to, albeit very briefly, unearth some of these roots. The primary concern of Kant's paper is to show that the controversy between Newton and Leibniz over the nature of space is to be resolved in favour of the existence of Newtonian absolute space. Kant's overall argument relies, in part, on the following claim,

Because of its three dimensions, physical space can be thought of as having three planes, which all intersect each other at right angles. Concerning the things which exist outside ourselves: it is only in so far as they stand in relation to ourselves that we have any cognition of them by means of the senses at all. It is, therefore, not surprising that the ultimate ground, on the basis of which we form our concept of directions in space, derives from the relation of these intersecting planes to our bodies. The plane upon which the length of our

\footnotetext{
${ }^{5}$ I discuss Taylor's claim in more detail in $\S 5$.

${ }^{6}$ Another line of thought, stemming from Husserl (1907), finds a constitutive relation between visual space and bodily activity in something like the following: the fact that perception is perspectival means that visually perceived objects are presented perspectivally. For example, the circular rim of my coffee cup is, from my present perspective, presented elliptically. Nevertheless, there is a clear sense in which the rim looks circular. Furthermore, the perspectival nature of visual space means that seen objects are presented as having both facing and rear sides, the former of which occludes the latter. These features of the visual presentation of objects are, it is claimed, to be explained in terms of a constitutive connection between visual space and bodily activity. A simple version of this view would claim that for the rim of my cup to look circular, despite its being presented as elliptical, is for it to look as though were I to move appropriately with respect to it, it would present a circular appearance (i.e. if I move so as to view it from above). A sophisticated version of this type of view is defended by Schellenberg (2007).

${ }^{7}$ This is, of course, prior to Kant's $(1781 / 1787)$ mature account of space as pure intuition.
} 
body stands vertically is called, with respect to ourselves, horizontal. The horizontal plane gives rise to the difference between the directions which we designate by the terms above and below. On this plane it is possible for two other planes to stand vertically and also to intersect each other at right angles, so that the length of the human body is thought of as lying along the axis of the intersection. One of these two vertical planes divides the body into two externally similar halves and furnishes the ground of the difference between the right and the left side. The other vertical plane, which also stands perpendicularly on the horizontal plane, makes possible the concept of the side in front and the side behind. (Kant $1768,366-7)$

So, on Kant's picture, our conceptual grasp of the left-right dimension is based upon our awareness of the difference between the left and right sides of our bodies. ${ }^{8}$ This latter awareness, Kant goes on to say, is not itself conceptual but sensory, and has a close tie with certain active capacities, "Since the distinct feeling of the right and the left side is of such great necessity for judging directions, nature has established an immediate connection between this feeling and the mechanical organisation of the human body." $(1768,369)$. The fact that it is nature that establishes this latter connection suggests that Kant perhaps does not take it to be constitutive of our concept of egocentric, oriented space, but rather merely empirical. Indeed, it is not clear that Kant is making any constitutive claim here. Rather, the most natural reading is that he is proposing an account of how we acquire the concepts left and right, and the others. That Kant's remarks concern concept acquisition obscures the commonsensical observation that not only do we possess the concepts left and right, our (visual) sensory experience is also structured by this and the other mentioned dimensions. This observation is entirely in keeping with Kant's claim that handedness, a feature that depends, he argues, on a body's relation to absolute space, "can be immediately perceived" (1768, 369).

In his account of the spatiality of Dasein, Heidegger $(1927, \S \S 22-24)$ briefly discusses Kant's account of spatial orientation in terms of a 'feeling of the right and the left side'. Heidegger is critical of Kant's account, replacing it with one in terms of activity and being-in-the-world, "Left and right are not something 'subjective' for which the subject has a feeling; they are directions of one's directedness into a world that is ready-to-hand already. 'By the mere feeling of a difference between my two sides' ${ }^{\prime \prime}$ I could never find my way about in a world." (Heidegger 1927, 143). It is not the

\footnotetext{
${ }^{8}$ See also the discussion of spatial orientation in (Kant 1786).

${ }^{9}$ Here Heidegger refers to (Kant 1786).
} 
present concern to determine whether this, suitably elaborated, is a fair criticism of Kant. Rather, the point is to trace a line of thought to its expression in Merleau-Ponty's account of the constitutive relation between egocentric space and bodily activity. It is notorious that Heidegger's account of being-in-the-world downplays the role of embodiment and his account of orientation is no exception..$^{10}$ Indeed, one fruitful way of reading Merleau-Ponty's account of the perception of space, is as filling out this lacuna and, in a sense, bringing Kant back into the Heideggerian account. The key to this reconciliation of sorts, is his claim that, "the body is the vehicle of being in the world" (Merleau-Ponty 1945, 84). Being-in-the-world is, amongst other things, a bodily attitude to the world in which the world appears as a practical, emotional and, above all, meaningful landscape. As such, an account of spatial orientation in terms of being-in-the-world is an account in terms of the body. It is thus no surprise to find in Merleau-Ponty a statement of the view that, "[w]hat counts for the orientation of the spectacle is not my body such as it in fact exists, as a thing in objective space, but rather my body as a system of possible actions" (Merleau-Ponty 1945, 260). With this statement of Act-Space we, arguably, see the influence of both Kant and Heidegger. It is this view that will be my target. $^{11}$

What follows is an evaluation of the case for Act-Space. In particular, in §§3-4, I look at two ways of construing an argument for it that can be drawn from Merleau-Ponty. Both of these rely, albeit in different ways, on empirical work concerning the inversion of the retinal image. I will argue that it is likely that the first, and simplest, way of construing the argument can be shown to rest on a false empirical claim. The second way of construing the argument is potentially more successful. However, I argue that Merleau-Ponty's argument rests, at a crucial point, on a conflation of two notions: the direction up, on the one hand, and the top of the visual field, on the other. The most

\footnotetext{
10 "Out of this [Dasein's] directionality arise the fixed directions of right and left. Dasein constantly takes these directions along with it...Dasein's spatialization in its 'bodily nature' is likewise marked out in accordance with these directions. (This 'bodily nature' hides a whole problematic of its own, though we shall not treat it here)." (Heidegger 1927, 143).

${ }^{11}$ There is, arguably, another respect in which Merleau-Ponty's account of space is Kantian. It is instructive to consider Merleau-Ponty's criticisms of the Empiricist and Intellectualist accounts of space in Kantian terms. On one view, Merleau-Ponty's case against the Empiricist is essentially against the transcendental realist, who supposes space to be a thing in itself, or perhaps, a system of relations between things in themselves. Merleau-Ponty's case against the Intellectualist, on the other hand, is against the Kantian transcendental idealist, who supposes space to be the mere form of intuition - a condition of the possibility of sensibility. The question, then, is whether this makes Merleau-Ponty's account of space a transcendental idealism of another sort. On the assumption that the falsity of transcendental realism entails the truth of transcendental idealism, one might answer this affirmatively. The difference, on this reading, between the Kantian and the MerleauPontian forms of transcendental idealism would be, of course, in the role that Merleau-Ponty accords to the active body in the determination of the formal qualities of space. Although the Kantian account of space allows for a significant role for the body, Merleau-Ponty makes it clear, in his account of 'lived space', that he does not accept that the 'shape' of space is a necessity that can be determined apriori and, in this respect, he departs from Kant. In what follows, however, I will be assuming that Merleau-Ponty's arguments for Act-Space can be assessed independent of these broader metaphysical issues.
} 
that can be drawn from Merleau-Ponty's line of argument is, I claim, the Kantian claim that there is a connection between egocentric, oriented space and the (phenomenal) body. In $\S 5$ I turn to a contemporary line of argument for Act-Space. This argument employs the notion, familiar from both psychology and linguistics, of a spatial frame of reference. I argue that, as with the Merleau-Pontian arguments, whilst Act-Space is not fully vindicated, there are, once more, some considerations that favour the weaker Kantian claim concerning the relation between oriented space and the (phenomenal) body. First, however, it is worth offering something of a further specification of ActSpace itself.

\section{Act-Space and intelligent trees}

The claim that there is a constitutive relation between the egocentricity of visual space and bodily activity can be formulated in a number of ways. Those different formulations will potentially support different claims about the relation between spatial perception and bodily activity. Generic versions of these might include the following,

The Activity Claim: Egocentric spatial perception requires an active subject.

The Capacity Claim: Egocentric spatial perception requires a subject capable of activity.

The Conceptual Claim: Egocentric spatial perception requires a subject capable of grasping (understanding) activity.

The Definitional Claim: Egocentric spatial perception is defined in terms of activity, (although a subject need not be active, capable of activity, or have a grasp of activity in order to enjoy egocentric spatial perception).

These formulations place different demands on what subjects with egocentric spatial perception must be like. The Activity Claim limits egocentric spatial perception to non-stationary subjects, that is to subjects that actually engage in active bodily movement. The Capacity Claim allows that stationary subjects could enjoy egocentric spatial perception, but denies it to those subjects, perhaps include those suffering from permanent and total body paralysis, that lack the capacity to so act. The Conceptual Claim allows that such paralysed subjects might have egocentric spatial perception, but denies that this would be so were they not to grasp the concept of bodily activity. Finally, the Definitional Claim allows that all the above-mentioned subjects might enjoy egocentric spatial perception maintaining, however, that there is nevertheless a conceptual connection between such perception and bodily activity. So, whilst one could not possess the concept of egocentric spatial perception if one lacked the concept of bodily activity, one may enjoy egocentric perception without being an agent. In effect, the definitional claim, in itself, places no restrictions on 
what egocentric spatial perceivers must be like. Of course, one might claim that in order to be in states that are defined in terms of their relation to bodily action, one must act/be capable of activity/grasp the concept of activity. But, in itself, the definitional claim does not insist on this. ${ }^{12}$

There is an apriori argument that, if convincing, would tell against all but the definitional variation of Act-Space. Dummett (1964) asks us to imagine a race of intelligent trees, incapable of activity and, we can also suppose, lacking the concept of activity (active movement). Nevertheless, they occupy a world of moving bodies, which they visually perceive as such and as laid out in egocentric space. ${ }^{13}$ Is such a thing conceivable? It certainly seems to be. If, as many have held, conceivability is a good guide to possibility, then we have some reason to doubt the Activity, Capacity and Conceptual Claims. ${ }^{14}$ I take, it, however, that the definitional claim has at least the potential to survive the possibility of intelligent trees. For the definitional claim makes no demands on what egocentric perceivers must be like. I am not going to pursue this objection. I note it here simply to set it aside by adopting the definitional claim as an interpretation of Act-Space. It should also be borne in mind that, in what follows, my claim will not be that Act-Space is false, but that a number of potential arguments in its favour are not compelling. ${ }^{15}$

\section{Inverted retinal images}

Merleau-Ponty's discussion of spatial perception begins in earnest with a discussion of some wellknown experiments by Stratton (Stratton 1896; 1897) using inverting prisms. In brief, Stratton wore, for an extended period, goggles with prisms that inverted the retinal image. To begin with, according to Stratton, his visual field seemed inverted and he found action very difficult. However, after a number of days of continuous use, and engagement in normal activity, there was both behavioural adaptation - he was able to engage in 'normal', unreflective activity-and perceptual adaptationthe visual field was spontaneously re-inverted. That is, everything now seemed the right way up! After a dismissal of Stratton's own explanation of this result as "unintelligible" (Merleau-Ponty 1945,

\footnotetext{
${ }^{12}$ Obviously, one might endorse a combination of the above claims. For one thing, on a suitable reading of 'capacity', the activity claim obviously entails the capacity claim. One might even suppose that all four claims are true.

${ }^{13}$ In a similar vein, Schellenberg $(2007,610)$ considers a sentient statue, and Galen Strawson (Strawson 1994, ch.9) offers the example of the 'weather watchers'. Each of these challenges the claim that the subject of egocentric spatial perception move, have the capacity to move, or grasp the concept of self-movement. Less radical examples might challenge only the contention that the subject's movement be active.

${ }^{14}$ See, for example, the essays in (Gendler and Hawthorne 2002).

${ }^{15}$ An empirical argument against Act-Space might rest on the evidence for the 'two-visual systems' hypothesis that separates vision for action and vision for conscious perception. I will not pursue this issue. For discussion, see (Clark 2001; Campbell 2002, ch.3; Briscoe 2009).
} 
256), Merleau-Ponty proposes his own account of the orientation of the visual field which is, as we have seen, that it is determined by the body as a "system of possible actions" (Merleau-Ponty 1945, 260). Prior to a consideration of the detail of Merleau-Ponty's case either against Stratton or in favour of his own view, it is helpful to take a step back and enquire about Merleau-Ponty's broader argumentative strategy in Phenomenology of Perception, in particular, his relation to the large body of empirical literature that he discusses. We can, following Komarine Romdenh-Romuluc $(2011,24-$ 34), distinguish between two views. On one, Merleau-Ponty's use of empirical literature is entirely negative. It serves at least two functions, one of which is to highlight internal inadequacies of opposing views, the other of which is to bring to attention unobvious features of various phenomena, features that become manifest when ordinary, unreflective experience breaks down. ${ }^{16}$ I call this the heuristic strategy. On another view, that taken by (Romdenh-Romluc 2011), MerleauPonty's use of empirical literature is, on at least some occasions, broadly empirical in intent. That is, some of Merleau-Ponty's arguments for his own views have empirical premises. ${ }^{17}$ I call this the empirical strategy. If the empirical strategy is correct, perhaps we can understand Merleau-Ponty's use of Stratton's results in this way. That is, perhaps Merleau-Ponty's argument is an inference to the best explanation: the constitutive link between egocentric space and bodily activity explains perceptual adaptation. If so, the first thing to evaluate is the evidence for perceptual adaptation. I do this in the remainder of the present section, arguing that the evidence for perceptual adaptation is weak and so the empirical strategy fails. I leave until the next section any consideration of the heuristic strategy.

Stratton's experiment has been replicated many times and the results have been mixed. For example, in an early study Ewart (1930) reported no perceptual adaptation, whereas Kohler (1951), after a series of experiments, did. As recently as the late 1990s, the controversy was described by Gregory $(1998,142)$ as unresolved. One recent study, (Linden et al. 1999), reported behavioural but no perceptual adaptation and added the following piece of evidence: there is no reversal of depth cue information. Depth cue information is sensitive to up/down inversion, concave becomes convex and vice versa. Linden et. al. report that judgements based on depth cues showed no sign of

\footnotetext{
${ }^{16}$ See, for example, (Gardner Forthcoming).

${ }^{17}$ My own view is that whilst it is plausible to read some of Merleau-Ponty's use of empirical material as purely heuristic, it is not possible to read all of his work in this way. Thus, Merleau-Ponty relies on both heuristic and empirical strategies. However, the interpretation of Merleau-Ponty as adopting the empirical strategy does make problematic what he says about his own relation to Husserl. I discuss this issue in (Smith 2005). Nothing in the present discussions relies upon what stand we take to this question of interpretation.
} 
reverting to normal at any point during the experiment. This appears to corroborate the participants' claims that there was no perceptual adaptation. ${ }^{18}$

All of this should lead us to treat claims concerning perceptual adaptation with caution; the jury is still out. ${ }^{19}$ As such, the prospects for an inference from perceptual adaptation to Act-Space seem dim. An alternative argument has been proposed, however. Whilst Noë (2004) does accept that perceptual adaptation occurs, he also has an argument for his version of the constitutive relation between egocentric space and bodily activity that does not depend on it. Rather, it depends on claims made in Kohler (1951) to the effect that upon putting on inverted goggles, the immediate effect is not that the world appears inverted, but that one is, as Noë puts it, 'experientially blind' one has visual sensations, but cannot see anything, "The initial effect of inverting glasses of this sort is not an inversion of the content of experience (an inversion of what is seen) but rather a partial disruption of seeing itself. Inverting lenses give rise to experiential blindness...This is exactly what the enactive approach would lead us to expect" (Noë 2004, 8).

Experiential blindness is predicted, says Noë, by his version of Act-Space (enactivism) since, on his view, to experience something as to the left is to experience it as occupying a position of which one 'grasps' that one would need to move one's hand to the left in order to point there, and that various further sensori-motor contingencies hold. Since, with retinal inversion, one's bodily activity and visual sensation are not appropriately coordinated, these sensori-motor contingencies are disturbed. Thus, one will have visual sensation without seeing or, at least, with only 'partial' seeing.

But the evidence for experiential blindness is not strong. Whilst various subjects have reported that inverting goggles make objects seem unusual, or unreal, few have reported the extreme effects described by Kohler, who says that he, "felt as if [he] were living in a topsy-turvy world of houses crashing down on you, of heaving roads, and of jellylike people" (Kohler 1951, 64). ${ }^{20}$

\footnotetext{
${ }^{18}$ Assuming that such negative results are not the result of some flaw in the experimental design, or reflective of idiosyncrasies in test subjects, one may well wonder how Stratton and others could have been wrong about such an apparently obvious matter as whether their visual field is inverted. One suggestion would be that subjects' behavioural adaptation makes the inverted field seem normal and encourages them to overlook their own phenomenology, they simply don't notice that their visual field is inverted. Compare these responses to a related experiment by Asch and Witkin, "In general, these Ss expressed deep surprise when they saw the mirror upon removing the tube from the face. One subject reported: 'I am astounded. I didn't think it was possible to make such a mistake.' Another asserted: 'I was completely absorbed in the picture. It seems hard to believe that the room was tilted, everything appeared perfectly straight."' (Asch and Witkin 1948, 32).

${ }^{19}$ For a recent claim that left-right perceptual adaptation occurs, see (Sekiyama et al. 1996).

${ }^{20}$ In fact, this report is not from a retinal inversion experiment at all, but one in which Kohler wore spherical prism glasses, the primary effect of which seems to have been the curvature, expansion and contraction of visually perceived objects (Kohler 1951, 64-6). Given this, one might very well expect the sort of 'jellylike' effects that Kohler describes. What about true inversion experiments? Well, given that experiential blindness
} 
Indeed, as Lycan $(2006,11)$ points out, the description that Kohler gives, and that Noë cites, does not even prima facie support the interpretation of experiential blindness. What Noë seems to mean by experiential blindness is that one's visual experiences lack content. He describes the experientially blind as those who "have sensations, but the sensations don't add up to experiences with representational content" $(2004,5)$. But, supposing that one is happy to talk in such terms, it seems reasonable enough to suggest that Kohler's distorted visual experience represents the roads as heaving, the people as jellylike, etc. We can conclude, then, that Noë's argument from experiential blindness is unconvincing. ${ }^{21}$ With this, I leave the empirical strategy.

\section{The orientation of the visual field}

The heuristic interpretation of Merleau-Ponty use of Stratton is less straightforward than an inference to the best explanation from perceptual adaptation to Act-Space. Perhaps, at least in part, the function of the Stratton experiment is to open our eyes to an unobvious feature of the visual presentation of space. In introducing Stratton, Merleau-Ponty suggests that we, "consider this experience of space prior to any theoretical elaboration. Take, for example, our experience of "up" and "down" [du "haut" et du "bas"]. We cannot grasp this experience in the everyday course of life, for it is already concealed beneath its own acquisitions. We must look to some exceptional case in which it breaks down and rebuilds itself before our eyes, such as in the case of vision without retinal inversion." (Merleau-Ponty 1945, 254-5). ${ }^{22}$ But what do we thereby learn? What might Stratton's experiment show us that would be best explained by Act-Space? It is, I suggest, that the orientation of visual space is relative, that, "[w]e need an absolute within the relative" (Merleau-Ponty 1945, 258), and that that absolute is the body, "as a system of possible actions" (Merleau-Ponty 1945, 260).

is claimed by Noë to be the immediate effect of retinal inversion, it is rather easy to test for. I have done so both on myself, and a significant number of others, and have neither experienced, nor had it reported, that anything resembling Noë's experiential blindness occurs.

${ }^{21}$ If Noë's view really does predict experiential blindness in these circumstances, and none occurs, then that would seem to show that Noë's view is empirically inadequate. An analogous claim is argued for by (Klein 2007), based on the premise that perceptual adaptation does not occur. However, I hesitate to draw this conclusion based on either premise. First, I have not argued that perceptual adaptation does not occur, merely that it is questionable whether it does. Second, although I won't argue for it here, I rather doubt that Noë's view really does predict experiential blindness.

${ }^{22}$ Smith has 'up' and 'down' as 'top' and 'bottom' respectively. 
Space, as experienced visually, is oriented. Objects look to the right, or left, of each other. They are above, or below, each other, they are near or far. ${ }^{23}$ It is, perhaps, obvious enough that something is to the right of another only relative to a third point. When something appears to the right of another, that third point is, we might well assume, the location from which the scene is viewed. But it is not so obvious that above and below are relative in such a way. Won't one thing seem to be below another just in case it is between that other thing and the earth? The experience of wearing inverted goggles quickly disabuses us of this. For, in such experience, there is a clear sense in which, for example, the carpet seems to be 'above' the walls, and this even before any supposed perceptual adaptation has occurred. But if the experience of above and below is not determined by the position of the earth and its gravitational pull, the question arises as to what it is determined by. According to Merleau-Ponty, Stratton's experiment shows us that,

The oriented world, or oriented space, cannot be taken as given with the contents of sensory experience or with the body in itself since experience in fact shows that the same contents can, one by one, be oriented in one sense or another, and that the objective relations, recorded upon the retina by the position of the physical image, do not determine our experience of "up" and "down." [du "haut" et du "bas"] The question is precisely how an object can appear to us as "upright" or "inverted," ["droit" ou "renversé"] and what these words mean. (Merleau-Ponty 1945, 257) ${ }^{24}$

So the orientation of visual space is not determined by the world, or by the body in itself. I take it that a reason for thinking that the body in itself, what Merleau-Ponty also refers to as the body, "as a thing in objective space" (Merleau-Ponty 1945, 260), is not up to the task is that it is plausible to suppose that that which determines the orientation of visual space must itself be something within experience. To see this, consider what one's experience would be like if one were to simultaneously invert every sensory modality, including proprioception and one's sense of the pull of gravity. It is natural to think that such total inversion would be indiscriminable from the

\footnotetext{
${ }^{23}$ I do not distinguish here between looking $F$, looking like an $F$ or looking as though $F$. While there are important differences between these, see for example (Martin 2010), and their application to the case of egocentric spatial relations is of interest, I abstract from it in the present discussion.

${ }^{24}$ This passage, in particular the claim about what experience shows, may be interpreted as relying on the claim perceptual adaptation occurs. If so, it is subject to the same concerns as is the empirical strategy. However, we might read the passage as claiming, more modestly, that the same visual scene can be differently oriented, for example before and after donning the inverting goggles. For the sake of offering Merleau-Ponty an alternative to the empirical strategy, I will presume the latter reading.
} 
normal case, for there would, by hypothesis, be no element of one's experience upon which to base a discrimination of the two cases. ${ }^{25}$ If so, then the orientation of visual space is not determined simply by the objective position of the body. Plausibly, to change the orientation of visual space one must change some further aspect of experience.

Merleau-Ponty considers the suggestion that the orientation of visual space is determined by "consciousness of one's own body", rejecting it on the grounds that, "[a]s a mass of tactile, labyrinthine and kinaesthetic givens, the body has no more precise an orientation than the other contents, and it itself receives this orientation from the general level [niveau] of experience", thus "the body, considered as a mosaic of given sensations" (Merleau-Ponty 1945, 260) is insufficient to determine visual orientation. To further support this, Merleau-Ponty points out that, "my body can nevertheless move without dragging along with it the orientations of up and down, such as when I lie down on the ground" (ibid). Instead, it is, "the body...as an agent [that] plays an essential role in establishing a level" (ibid).

There are at least two points to make against Merleau-Ponty's argument here. First, one might reject the view that the body as sensed, as presented in sensation, lacks orientation. Rather, sensations are given as located within an oriented bodily space, and that space has a definite top and bottom, a left and a right. This is a point made by O'Shaughnessy in his discussion of the sense of touch. He points out that the information gained through even the simplest touch sensation is, "something solid here" $(2000,662)$. But how, O'Shaughnessy asks, is the 'here' specified? His answer is that, "the data will be at least a complex as, on-the-right-index-finger-attached-to-hand-attachedto-arm-attached-to-etc." $(2000,663)$. Thus, sensations are presented as located in body-relative space. An itch on my forehead will be experienced as towards my body's top, a pain in my toe as towards its bottom.

Second, Merleau-Ponty seems to have conflated two senses in which visual space is oriented. So far in the discussion, I have followed him in not distinguishing these, but it is crucial, at this point, to bring this difference to the fore. We can distinguish between what looks to be up from what looks to be at the top of my visual field. Merleau-Ponty is surely correct to point out that, when I lie down, the direction that looks to be up, does not change. Even when standing on my head or, more pertinently, when wearing inverting goggles, there is a clear sense in which the sky still

\footnotetext{
${ }^{25}$ Actually, if the depth cues discussed in the previous section are sensitive not to the felt orientation of the body but to its objective orientation relative to some frame (e.g. gravity), then the cases would be discriminable. However, even if this were so, it is not clear that it would challenge the thought that, so far as orientation is concerned, the cases would be impossible to discriminate. Surely the sky would look to be at the top of the visual field.
} 
appears to be above the grass. This is particularly noticeable when, with goggles on, one looks at one's own body. When one does this, one's body doesn't look to be upside down. Rather, in such an experience, down is in the direction of one's gaze. Rather, one's body looks to be standing the right way up, but facing one. Something, however, does change. For one's body occupies a different part of one's visual field - the top. In fact, that the top of one's visual field ought to be distinguished from the direction up should be obvious from considering what one's experience would be like floating in a featureless zero-gravity environment. In such a case, there would be no up, but there would surely be a top and a bottom, a left and a right, of the visual field.

With this distinction in place, we can see how Merleau-Ponty's discussion, at least as I have been interpreting it, rests on this conflation. For the thought that the orientation of visual space is relative, was motivated by a situation in which what changes is what appears at the top of the visual field. Thus, what we should be looking for is not what determines up and down but what determines top and bottom. What determines what looks to be up and down, or so it is natural to suppose, is the apparent position of the earth and its gravitational pull. Down is the direction in which gravity appears to pull me. Such a claim must be qualified in light of the fact that the visual 'upright' is sensitive to various cues, including bodily tilt, that go beyond the sensed gravitational pull (Asch and Witkin 1948). Nevertheless, the fact remains that gravitational pull plays an important role. ${ }^{26}$

Whilst gravity plays such a role in the determination of up and down, it does not seem to do so with the top and the bottom of the visual field. This is determined by something else, a fact made very clear as soon as one puts on inverting goggles, or simply performs a handstand. But what is the orientation of the visual field relative to? One natural suggestion, of course, is that such orientation is determined by the body as it is presented in bodily, non-visual, experience; the body as a 'mosaic of given sensations'. On such a view, the top, bottom, left, and right of the visual field would be determined by the experienced location of one's body parts. Roughly, the top is where one's forehead feels to be, the bottom where one's nose seems, the left is where the left side of one's face seem to be, the right where the right seems. ${ }^{27}$

\footnotetext{
${ }^{26}$ Obviously this is a contingent fact. Had we, and our visual and cognitive systems, evolved in a zero-gravity environment, it would not have been so. For a discussion of visual orientation in zero-gravity, see (Howard \& Templeton 1966, ch.16), who write that, "under zero- $g$ a sense of up and down can originate only from the visual frame provided by the spacecraft, or from the felt position of the feet and head, assuming that objects outside the spacecraft are not in view...subjects are able to walk on an iron surface when wearing magnetic shoes, and...accept the surface upon which they walk as down." $(1966,424)$.

${ }^{27}$ This may seem, but is not, circular, not as long as one takes care not to explain this 'distinct feeling of the right and left side' in terms of the visually presented right and left. Cf. Noë's enactive account $(2004,87)$.
} 
Given the naturalness of this suggestion, and the apparent failure of Merleau-Ponty's argument against it, it seems that the heuristic strategy fails. Merleau-Ponty has not shown that there is a constitutive relation between the orientation of visual space and bodily activity, he has not shown that Act-Space is true. We haven't been given any reason to move beyond the position, close to that of Kant discussed above, that the orientation of visual space is determined by the felt orientation of the body.

Two objections might be raised to this tentative suggestion. First, it might be thought that it is empirically false, given the existence of deafferented, or 'body-blind', subjects, such as the well known case of IW, who nevertheless possess an oriented visual field. However, in fact, IW does not present a clear counterexample to the claim, since he has normal proprioceptive feedback from the neck upwards. Further, there is in fact some evidence that deafferented subjects' egocentric spatial representation is impaired (Cole and Paillard 1995).

Second, it might be argued that the present suggestion, even if not empirically false, is subject to an 'intelligent trees' style of objection. For we can imagine a subject, lacking all bodilyawareness, nevertheless possessing an oriented visual field. There are two responses that might be made here. One, analogous to the above response to the intelligent trees objection, is that the claim might be pitched at the definitional level. It is, however, difficult to see quite how this claim would be fleshed out. Another response would be to deny that a constitutive claim is being made here. First, as I argue in the next section, there is no reason to think that all visual fields have the same orientational structure with which we are familiar. Second, it is no part of the claim that a subject with an orientated visual field must possess an awareness of their own bodies, merely that it is this awareness that, at least typically, serves to determine the orientation of our visual field. ${ }^{28}$

\section{Egocentric frames of reference}

Neither of the two arguments for Act-Space that I drew from Merleau-Ponty are compelling. However, another argument, more recent, may fare better. This argument employs the notion of a frame of reference. In what follows I set this argument out in what I take to be its strongest form, then argue that whilst it fails to show that Act-Space is true, it, like Merleau-Ponty's heuristic strategy, does lend at least some plausibility to the claim that the orientation of visual space is determined by the apparent orientation of the body.

\footnotetext{
${ }^{28}$ This might be understood along the lines of Hurley's claim that perception and action are 'noninstrumentally dependent', see (Hurley 1998, 362-5).
} 
To begin, consider again Taylor's claim, one that he presents as an interpretation of Merleau-Ponty, and that I quoted in $\S 1$, that "[o]ur perceptual field has an orientational structure, a foreground and a background, an up and down. And it must have; that is, it can't lose this structure without ceasing to be a perceptual field in the full sense, i.e. our opening onto the world." (Taylor 1978, 254). This claim can be read in two ways. Taylor may be claiming that the visual field must have some orientational structure or other, or he may be claiming that it must have the particular orientational structure described (foreground, background, up, down and, one might add, left and right). ${ }^{29}$ Suppose that Taylor intends the second interpretation. The argument specifically mentions the up/down dimension. However, given the distinction above between up and the top of the visual field, I think we ought to read Taylor's as meaning the latter. Is it plausible to say that the visual field necessarily has a top and a bottom? It might seem so. It might be thought that we simply can't imagine what it would be like for our perceptual field to lack a top and bottom. If this is right, then we might be persuaded to agree with Taylor, that if our visual field lost its top/bottom, it would cease 'to be a perceptual field in the full sense'.

But we have moved too quickly here. It can be objected that, on this interpretation, Taylor's claim is anthropomorphic. Consider the case of Eyeball. Eyeball is an intelligent creature inhabiting some, not so remote, possible world. Eyeball's body consists of a giant, perfectly spherical eyeball, through which he can see in every direction at once. Eyeball is able to perceive his environment, and move around in it accordingly. Eyeball has the advantage that no-one can ever sneak up behind him, but the disadvantage that he can never turn his back on anybody. No doubt, none of us can know, or perhaps even imagine, what it is like to have the sorts of visual experiences that Eyeball has. But we should not doubt that Eyeball has visual experiences. The question to be asked is whether Eyeball's visual field has a top and bottom. I see no reason to suppose that it would. The point is that even if we cannot imagine what visual experience would be like if there were no top to the visual field, we do not yet have a reason to think that it is not possible. And if this is right, Taylor's claim, at least on this interpretation, cannot be accepted.

On the alternative interpretation, Taylor is claiming that the visual field must have some orientational structure or other. This claim, we can suppose, is immune to the charge of anthropomorphism. Now, according to Taylor, the visual field has the structure that it does, "because it is experienced as a field of potential action" $(1978,155)$. This, says Taylor, is because, "up and down are related to how one would move and act in the field. For it is only as a bodily agent functioning in a gravitational field that 'up' and 'down' have meaning for me." (1978, 154-5). Thus, we come to the conclusion that, "our perception of the world is essentially that of an embodied

\footnotetext{
${ }^{29}$ Taylor speaks of the perceptual field, rather than the visual field. I take it that it is vision that provides the most plausible case of a sensory modality that is essentially spatially oriented.
} 
agent, engaged with, or at grips with the world." $(1978,154)$. Thus, Taylor endorses Act-Space, the claim that there is a constitutive link between the orientation of visual space and bodily activity.

In the terms introduced in $\S 2$, Taylor defends the, potentially problematic, Activity Claim. We can, however, avoid this, and also sharpen the argument somewhat, by introducing the notion of an egocentric frame of reference, a strategy pursued by John Campbell $\left(1993 ; 1994\right.$, ch.1). ${ }^{30}$ The claim that visual space is egocentric is, as I said above, the claim that visual perception presents space from somewhere. This, I have been suggesting, has at least two consequences. First, objects are presented as bearing various spatial relations to each other. These include above, below, to the left of, and to the right of. Second, the visual field itself has a top, bottom, left, right. In the discussion of Merleau-Ponty, I argued that it is important to distinguish between these features of egocentric space. At this point, however, it is important to introduce a third, intuitive, feature of egocentric space. This is that visual space is self-locating. That is, vision carries information about my location (or, perhaps, the location of my body). ${ }^{31}$ This is the location from which worldly objects and their spatial layout are visually presented.

Taylor's argument, on one interpretation, was objected to on the grounds that it is anthropomorphic. Now this objection is an instance of a general point made by Campbell concerning frames of reference. Campbell's aim is to define the notion of an egocentric frame of reference; to give an account of the difference between an egocentric and a non-egocentric frame of reference. This relates to our current concern for the reason that, like any representation of space, visual perception employs frames of reference to represent the spatial relations between perceived objects. Thus, we might suppose that we can enquire into the conditions of egocentric space by asking what it is that makes a frame of reference egocentric. One way to approach this is to ask what is it that distinguishes visual space from a map-like spatial representation. For maps are surely not egocentric, most obviously in the sense that they are not self-locating. ${ }^{32}$ Thus, we might expect an account of the egocentricity of frames of reference to tell us about the egocentricity of visual space.

\footnotetext{
${ }^{30}$ What follows is one way of understanding what Campbell is up to. It may be possible to read him as making more modest claims. Further, much of the argumentative material filled out below has been introduced by me and is not Campbell's. Indeed, it is important to point out that (Campbell 2002) presents a rather different picture.

${ }^{31}$ There is a question as to whether perceptual content is 'self-referential' or 'self-indicating', that is, whether the content of perception 'door ahead of me' or 'door ahead'. On the self-referential view, perceptual content contains the ' $I$ ' concept, or perhaps its non-conceptual analogue. On the self-indicating view, perceptual content does not contain the 'I' concept, but, since the perceptually presented 'door ahead' a priori entails 'door ahead of me', has content may nevertheless justify the corresponding 'I' content. For the self-referential view, see (Peacocke 1999, 264). For the self-indicating view, see (Campbell 1994, 119). I discuss a related issue concerning bodily awareness in (Smith 2006).

${ }^{32}$ Cf. (Kant 1768, 367-8).
} 
Returning to the anthropomorphism concern, Campbell writes that, "an approach which tries to define what it is for a frame to be egocentric by simply listing a set of axes will not work. Again, there is no reason to suppose that all species will use the same egocentric axes" (Campbell $1993,74)$. Campbell's alternative to this 'extensional approach' to defining the notion of an egocentric frame of reference is to consider 'how the subject is apprehending those axes'. That is, what is distinctive of an egocentric frame of reference is not the axes used, but the way in which those axes are 'apprehended' by the subject. Note that Campbell's claim can be understood as a version of the Definitional Claim (see §2). The aim is to provide a definition of egocentricity. This he does in terms of bodily activity, thereby endorsing a version of Act-Space according to which, "the axes that are distinctive of an egocentric frame are those which are immediately used by the subject in the direction of action" (Campbell 1993, 75).

But what is a frame of reference, and how might one argue for the claim that egocentric frames of reference are those that are constitutively related to bodily activity? The idea that spatial representations employ frames of reference is a common one. The notion of a frame of reference is best approached by example. Consider the following perceptually presented scene:

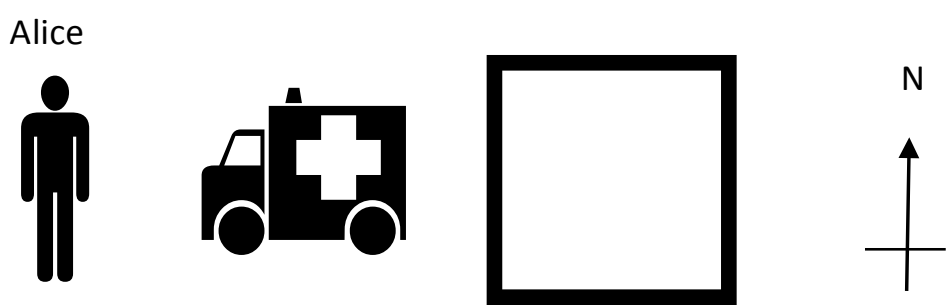

fig 1.

Here we can say that Alice is to the left of the ambulance. However, we can also say that she is in front of the ambulance, without thereby implying that either has moved. The reason is that in each case we are employing a different frame of reference. We might think of a frame of reference as a way of specifying the spatial relations between objects. More carefully, a frame of reference is an origin and set of axes that define a direction system. Thus, relative to one origin and set of axes, Alice is to the left of the ambulance, relative to another she is in front of it. When we say that Alice is in front of the ambulance, it is natural to think that the axes employed are the left/right, front/back axes, and the origin is the ambulance. When we say that the person is to the left of the ambulance, it 
is natural to think that the axes employed are the left/right, front/back axes, and the origin is the viewer ${ }^{33}$.

With these notions introduced, we can move on to a more elaborate characterisation of the different kinds of frame of reference. This is not the place to evaluate the competing views on how to distinguish between different kinds of frame of reference. Instead, I shall simply outline what I take to be the most illuminating view. This is the framework proposed by Levinson $(1996 ; 2003)$. This framework is described at the level of linguistic representation, so we must briefly turn to language.

Levinson distinguishes between three kinds of frame of reference: intrinsic, absolute and relative. An intrinsic frame of reference is an object-centred set of axes, with co-ordinates determined by the intrinsic features of the object. A spatial relation described by an intrinsic frame of reference can be called an intrinsic spatial relation. Intrinsic spatial relations are two-place relations, holding between the object upon which the axes are centred (ground) and the object whose position is determined relative to it (figure). For instance, in the above example, the sentence "the man is in front of the ambulance" employs an intrinsic frame of reference. The set of axes are centred on the ambulance (ground), and co-ordinates are determined by its intrinsic features, i.e. its front and back, and its left and right-hand sides. Any object which has intrinsic features suitable for defining such co-ordinates can act as the origin of an intrinsic frame of reference. For instance, returning to fig. 1 , "the cube is behind the ambulance" employs an intrinsic frame of reference, the origin of which is the ambulance. This is because the ambulance has an intrinsic front, back, left and right. However, "the ambulance is behind the cube" does not employ an intrinsic frame of reference, the origin of which is the cube. This is for the simple reason that the cube doesn't have the intrinsic features required to specify its back. If it could ever be true to say that the ambulance is behind the cube, there must be some other (non-intrinsic) frame of reference in play ${ }^{34}$.

An absolute frame of reference makes use of some fixed set of co-ordinates. An example, discussed in $\S 4$, is the up/down axes determined, at least in part, by the force of gravity, another is the set of axes comprising north/south/east/west. Absolute frames of reference specify the spatial relation that holds between two objects (figure and ground) in terms of these 'external' fixed coordinates. For instance, the sentence "Alice is west of the cube" employs an absolute frame of reference. The axes used are the north/south/east/west axes, and the origin is the cube. A spatial

\footnotetext{
${ }^{33}$ According to the framework proposed below, these intuitive analyses turn out to be slightly misleading. They serve well enough to introduce the notion, however.

${ }^{34}$ Levinson (1996) argues that whether a given object is regarded as having such intrinsic features varies across different cultures. To this extent it might be regarded as infelicitous to call such features intrinsic, since we do not think of an object's intrinsic features as relative in this way. I shall ignore this worry, however.
} 
relation described by an absolute frame of reference can be called an absolute spatial relation. Absolute spatial relations are two-place relations holding between figure and ground. As with intrinsic frames of reference, the origin of the axes is always centred on the object that is the ground.

Relative frames of reference differ from both the intrinsic and absolute in that the spatial relations they describe are three-place relations. They involve, not only a figure and ground, but also a viewpoint. They use axes centred on the viewpoint to assign positions to both figure and ground. For example, the sentence "Alice is to the left of the ambulance" is true of fig 1. But this clearly is not employing an absolute frame of reference, neither is it employing an intrinsic frame of reference, since the person is to the intrinsic front of the ambulance. Rather, it employs a relative frame of reference. Alice is to the right of the ambulance relative to the viewpoint of the speaker. Notice that the viewpoint which is the origin of the axes of a relative frame of reference need not be the speaker, for we can say, "from Alice's point of view, the ambulance is in front of the cube", thereby employing a relative frame of reference, the axes of which are centred on the viewpoint of another individual, Alice.

After this diversion, let us return to perceptual experience. For the sake of argument, we can make the following assumptions: first, that perceptual states represent the world as being a certain way spatially; ${ }^{35}$ second, that these representations employ frames of reference; and third, that all three kinds of frame of reference are employed in the perceptual representation of space. Are we now in a position to determine in virtue of what it is that perception is egocentric? Arguably not. To see this, consider a map, the paradigm of a non-egocentric spatial representation. Think of this map as a photograph taken by a satellite positioned directly above you. The photograph contains you as an element, as it does the various things around you including, say, other people. This map represents the spatial relations between different objects in your environment and also between those objects and yourself. Furthermore, it conveys information in intrinsic, absolute and relative frames of reference. Yet this map does not have the orientational structure characteristic of egocentric space. It does not, of itself, tell you where you are. Pointing out that perception uses frames of reference that are intrinsic, absolute or relative does not seem to provide us with the materials with which to define egocentricity. Therefore, egocentricity cannot be defined in terms of the kind of frame of reference.

\footnotetext{
${ }^{35}$ I make this assumption for ease of presentation. In fact, I assume that those who accept a nonrepresentational theory of perception could accept the gist of what I say in the following, with suitable adjustments.
} 
Call a frame of reference centred on the viewer/speaker a 'viewer-centred frame of reference' ${ }^{36}$ It is sometimes claimed that perceptual states necessarily represent spatial relations in a viewer-centred frame of reference ${ }^{37}$. According to this method of classifying frames of reference, any kind of frame of reference (intrinsic, absolute, or relative) can be either viewer-centred or not. Is it correct to claim that perception necessarily employs viewer-centred frames of reference? There are two ways of understanding this claim. On one understanding I take it to be almost certainly false, on the other it is true but not what we require.

The first (almost certainly false) of these is to understand the claim as meaning that every perceptual representation of space employs a viewer-centred frame of reference only. If this were true, it would entail that my yard cannot look to be in front of my house. For that employs a nonviewer-centred frame of reference. Similarly, consider fig. 1 again, it would have the consequence that the person cannot look to be in front of the ambulance. I take these consequences to be highly counterintuitive and suggest that, on this way of understanding it, the claim that perception necessarily employs viewer-centred frames of reference is false.

But there is another way of understanding the claim. We can understand it as the claim that every visual experience must have at least some content which employs a viewer-centred frame of reference. Typically, every visual state has a vast amount of representational detail. So, for example, if presented with fig. 1, the person looks to be in front of the ambulance, and the ambulance looks to be to the right of the person, and the ambulance looks to have a cross on it, and so on. On this second way of understanding the claim, although some of the content of a perceptual state may employ a non-viewer-centred frame of reference, not all of it can. There must be some part of the content that employs a set of axes whose origin is the perceiver.

This seems rather plausible. It stems from the fact that to see something is to see it from somewhere. Thus, some of the content of any perceptual state will represent the spatial relations holding between the perceiver and the objects perceived. As was pointed out earlier, if perception is always perception from somewhere, it seems inconceivable that the content of a perceptual state could fail to include some information as to the position of the perceiver (or their body).

\footnotetext{
${ }^{36}$ Or a part of the viewer/speaker. It is plausible that in order to give an adequate explanation of the way in which spatial representations feed into action, it is necessary to employ a variety of viewer-centred frames of references, centred on different parts of the body. See, for example (Paillard 1991), in particular, the papers by Berthoz; Roll, Roll \& Velay; and Paillard.

${ }^{37}$ See, for instance, (Bryant 1997, 247-8), although he uses the term 'egocentric' I think it is clear that he means what I mean by 'viewer centred'.
} 
True as this may be, it does not yet help us to understand what is so special about the way in which vision represents spatial relations, and therefore it does not help us in our aim of defining egocentric frames of reference. To see this we need to consider, what we might call, Perry cases. ${ }^{38} \mathrm{~A}$ Perry case occurs when someone perceives or denotes herself without realising it. The most famous example is that of Oedipus. If Oedipus were to utter the words "Jocasta is standing behind the slayer of Laius", he would be denoting himself but without realising it. Indeed, he would be employing an intrinsic, viewer-centred frame of reference, but without realising it. Turning to the perceptual case, we can imagine someone who doesn't realise that she is looking into a mirror, seeing the bogeyman who looks to be behind the woman in glasses. Here her perceptual state employs an intrinsic, viewer-centred frame of reference, but she doesn't realise it.

These cases show us that the current proposal, that all perceptual states contain some viewer-centred content, cannot be what is special about the perceptual representation of spatial relations; cannot account for egocentricity. For it is entirely consistent with this proposal that all the viewer-centred content of a perceptual state be like a Perry case. But surely this is not conceivable. Perception just isn't like that, it is self-locating. So, in order define egocentricity, and capture what is special about perception we are going to have to say more than that it necessarily employs viewercentred frames of reference.

So what is it for a frame of reference to be egocentric? It doesn't seem to be a matter of the kind of axes used, or a matter of where it is centred. Campbell's answer, of course, lies in the supposed intimate connection between the content of spatial perception and spatial action. Egocentric frames of reference are those that contain information that can be used immediately in action. Consider the fact, noted by Evans, that, "[e]gocentric spatial terms are the terms in which the content of our spatial experiences would be formulated, and those in which our immediate behavioural plans would be expressed" $(1982,154) .{ }^{39}$ Suppose I see a glass on a table in front of me. That part of the content of this perceptual state that specifies the spatial relation between me (or perhaps my hand) and the glass is immediately usable by me in action, e.g. in picking up the glass. Plausibly, an intention to pick up the glass will involve exactly that content. The next move in an argument for Act-Space would be to use this fact in a definition of an egocentric frame of reference. For this fact leads naturally to the suggestion that an egocentric frame of reference just is one that provides the subject with information that can be used immediately in the direction of action. As Campbell claims, "the axes that are distinctive of an egocentric frame are those which are immediately used by the subject in the direction of action." (Campbell 1993, 75).

\footnotetext{
${ }^{38}$ Cf. (Perry 1979).

${ }^{39}$ Also see (Peacocke 1992).
} 
This would mark a clear difference between the way in which perception represents the perceived environment, and the way in which a map does. The spatial relations between myself and my environment as represented in the satellite photograph map cannot be used immediately in the direction of action. For, I need also to know which thing on the map is me. Suppose that the map is of Trafalgar square, from above. I cannot, simply on the basis of the information given (without knowing which of the things represented is me), move towards Nelson's Column. However, this is not so with perception. Nothing more is required than that I see which direction Nelson's column is in. This, of course, is because perception is self-locating, or egocentric. And, the suggestion is, what it is in virtue of which visual space is self-locating, is that it can be used immediately in the direction of action. Thus, Act-Space is true.

I don't think that we should accept this argument for Act-Space. Our suspicion should have been aroused with the mention of Perry cases. For there is a simpler account available of how to explain why it is that visual space must be self-locating, and that is simply that it has first-personal content. That is, we should consider the claim that every visual experience must have at least some content that employs a viewer-centred frame of reference, where the viewer (or their body part) is picked out first-personally, as 'me' (or, as 'my body part'). ${ }^{40}$ This claim rules out the possibility that one's visual representation of space could be like a Perry case. This undercuts the motivation for moving to a definition of egocentricity in terms of bodily activity. Such a view can still maintain, with Evans, that the terms we use to describe egocentric space are those that we employ in forming intentions to engage in bodily activity. But it will deny that such a connection is constitutive of egocentricity. That is, we can accept Campbell's claim that, "the distinction between left and right...is evidently an axis used to direct action" $(1994,15)$, whist rejecting the claim that such use is definitive of the egocentricity of visual frames of reference.

So the argument for Act-Space is undermined, but do we now have, in the alternative, firstpersonal, account, all the materials needed for an account of egocentric space? Perhaps not, for I have only been considering how one might go about accounting for the self-locating character of egocentric space. I have said little, in the above argument, concerning the orientation of the objects of visual perception, or of the perceptual field itself. In fact, one can return to Merleau-Ponty to find the hint of an argument for the claim that the present account, in terms of first-personal viewercentred frames of reference, must be inadequate to explain the orientation of visual space. In his argument against the intellectualist account of spatial orientation, Merleau-Ponty claims that, "although a constituting mind eminently has the power to trace out all directions in space, in the

\footnotetext{
${ }^{40}$ Once more, if one is careful one will want to distinguish between self-referential and self-indicating views of the nature of self-location and, in my view, opt for the latter.
} 
present moment this mind has no direction and, consequently, it has no space, for it is lacking an actual starting-point or an absolute 'here' which could gradually give a direction to all the determinations of space [donner un sense á tout les déterminations de l'espace]" (Merleau-Ponty $1945,258) .{ }^{41}$ Here Merleau-Ponty claims that a non-located subject will lack an experience of space. I am assuming that the above account in terms of first-personal viewer-centred frames of reference, does give the subject a location. But can it give it, in Merleau-Ponty's words, a 'direction'? Points don't have a direction since they lack orientation. The fact that the first-person picks out the viewpoint as me (or mine) does not tell us its direction. But egocentric space is so oriented. It has a near and a far, a left and a right, and so on. So, arguably, an egocentric frame must be centred firstpersonally on something that is itself spatial, on something that itself occupies space. In this way, the intrinsic features of the viewpoint can be 'projected' out to determine the axes of egocentric frames of reference. The obvious thought here is that the viewpoint is represented as 'my body'. If this is right, and I won't do any more to defend the claim here, then we once more find ourselves with the Kantian sounding claim that that the orientation of visual space is determined by the orientation of one's own body. This is not quite the claim reached at the end of the previous section. But it dovetails with it. For the tentative result of the consideration of the heuristic strategy was that the orientation of visual space may be determined by the felt orientation of the body, whereas here the discussion has been limited to the representational content of visual experience. The two conclusions, when put together, would amount to the claim that egocentric space requires one to feel one's body occupying a first-personally specified point of view. ${ }^{42}$

\section{Conclusion}

I have argued that three ways of arguing for Act-Space are flawed. The empirical strategy, drawn from Merleau-Ponty's discussion of Stratton, is empirically unmotivated. The heuristic strategy, also drawn from Merleau-Ponty, seems to overstate the importance of bodily activity in determining the orientation of the perceptual field. The frames of reference argument, drawn from Campbell, does the same. However, I have suggested that the latter two arguments provide at least some reason to think that whilst Act-Space may not be motivated, an analogous claim about the representation of

\footnotetext{
${ }^{41}$ Smith renders 'sens' as 'significance'. I take it that Landes' translation makes better sense of MerleauPonty's thought here.

${ }^{42}$ Two points. First, one may attempt to launch an indirect argument for Act-Space from this claim. This might proceed via the claim that the phenomenal body is necessarily active, or via the claim that first-person representation is necessarily tied up with bodily activity as output. These are obviously major topics in themselves. Second, the claim itself will face similar objections to those mentioned in $\mathrm{fn} .27$.
} 
one's body may be. Egocentric space may not be, of necessity, an action space, but perhaps it is a body space. ${ }^{43}$

References

Asch, S. E., and H. A. Witkin. 1948. "Studies in Space Orientation: I. Perception of the Upright with Displaced Visual Fields." Journal of Experimental Psychology 38 (3): 325.

Brewer, B. 1992. Self-location and agency. Mind, 101(401), pp.17-34.

Briscoe, R. 2009. Egocentric Spatial Representation in Action and Perception. Philosophy and Phenomenological Research, 79(2), pp.423-460.

Bryant, D.J. 1997. Representing space in language and perception. Mind \& Language, 12(34), pp.239-264.

Campbell, J. 1994. Past, Space, and Self, Cambridge, MA: MIT Press.

Campbell, J. 2002. Reference and Consciousness, Oxford: Clarendon Press.

Campbell, J. 1993. The role of physical objects in spatial thinking. In N Eilan, R. McCarthy, \& B. Brewer, eds. Spatial Representation. Oxford: Oxford University Press.

Cassam, Q. 2002. Representing bodies. Ratio, 15(4), pp.315-334.

Clark, A. 2001. Visual Experience and motor action: are the bonds too tight? The Philosophical Review, 110(4), p.495.

Cole, J. \& Paillard, J. 1995. Living without touch and peripheral information about body position and movement: Studies with deafferented subjects. In J. L. Bermúdez, A. Marcel, \& N. Eilan, eds. The Body and the Self. Cambridge, MA: MIT, pp. 245-266.

Dummett, M. 1964. Bringing about the past. The Philosophical Review, 73(3), pp.338-359.

Evans, G. 1982. The Varieties of Reference. Edited by J. McDowell. Oxford: Clarendon Press.

Ewert, P.H. 1930. A study of the effect of inverted retinal stimulation upon spatially coordinated behavior. Genetic Psychology Monographs, 7, pp.177-363.

Gardner, S. Forthcoming. Merleau-Ponty's transcendental theory of perception. In M. Sacks, S. Gardner, \& M. Grist, eds. The Transcendental Turn. Oxford: Oxford University Press.

Gendler, T. \& Hawthorne, J. eds. 2002. Conceivability and Possibility, Oxford: Oxford University Press.

Gregory, R.L. 1998. Eye and Brain: The Psychology of Seeing, Oxford: Oxford University Press.

Grush, R. 1998. Skill and spatial content. Electronic Journal of Analytic Philosophy, 6(6).

Heidegger, M. 1927. Being and Time, translated by J. Mcquarrie \& E. Robinson. Oxford: Blackwell, 1962.

Howard, I.P. \& Templeton, W.B. 1966. Human Spatial Orientation, London: John Wiley \& Sons.

Hurley, S.L. 1998. Consciousness in Action, Cambridge, MA: Harvard University Press.

Husserl, E. 1907. Thing and Space: Lectures of 1907. Translated by R. Rojcewicz. Dordrecht : Kluwer, 1997.

\footnotetext{
${ }^{43}$ Thanks to audiences in Nottingham and York. Thanks in particular to Komarine Romdenh-Romluc, Jonathan Hale, Rafe McGregor and Ema Sullivan-Bissett for providing me with a deadline to write the paper, and to Tom Baldwin, John Schwenkler, Jack Wadham and Ann Whittle for helpful discussion.
} 
Kant, I. 1781/1787. Critique of Pure Reason. Translated and edited by P. Guyer \& A. Wood. Cambridge: Cambridge University Press, 1997.

Kant, I. 1768. Concerning the Ultimate Ground of the Differentiation of Directions in Space. Translated by D. Walford \& R. Meerbote. In D. Walford \& R. Meerbote, eds. Theoretical Philosophy, 1755-1770. Cambridge: Cambridge University Press, pp. 361372 (1992).

Kant, I. 1786. What is Orientation in Thinking? Translated by H. B. Nisbet. In H. S. Reiss, ed. Political Writings, second edition. Cambridge: Cambridge University Press, pp. 237249 (1991).

Klein, C. 2007. Kicking the Kohler habit. Philosophical Psychology, 20(5), p.609.

Kohler, I. 1951. The formation and transformation of the perceptual world. Translated by $\mathrm{H}$. Fiss. Psychological Issues, 3(4) (1964).

Levinson, S.C. 1996. "Frames of Reference and Molyneux's Question: Crosslinguistic Evidence." In Language and Space, edited by Paul Bloom, Mary Peterson, Lynn Nadel, and Merrill Garrett, 109-169. Cambridge, MA: MIT.

Levinson, Stephen C. 2003. Space in Language and Cognition: Explorations in Cognitive Diversity, Cambridge: Cambridge University Press.

Linden, D.E. et al. 1999. The myth of upright vision. A psychophysical and functional imaging study of adaptation to inverting spectacles. Perception, 28, pp.469-482.

Lycan, W.G. 2006. Enactive intentionality. Psyche, 12(3), pp.1-12.

Malpas, J. 1999. Place and Experience: A Philosophical Topography, Cambridge: Cambridge University Press.

Mandik, P. 1999. Qualia, space, and control. Philosophical Psychology, 12(1), pp.47-60.

Martin, M.G.F. 2010. What's in a look? In B. Nanay, ed. Perceiving the World. Oxford: Oxford University Press,.

Martin, M.G.F. 1992. Sight and touch. In T. Crane, ed. The Contents of Experience. Cambridge: Cambridge University Press, pp. 196-215.

Merleau-Ponty, M. 1945. Phenomenologie de la perception. Paris: Gallimard. Translated by Donald A. Landes as, Phenomenology of Perception, London: Routledge, 2012.

Noë, A. 2004. Action in Perception, MIT Press.

O'Shaughnessy, B. 2000. Consciousness and the World, Oxford: Oxford University Press.

O'Shaughnessy, B. 1980. The Will: a dual aspect theory, Cambridge: Cambridge University Press.

Paillard, J. ed. 1991. Brain and Space, Oxford: Oxford University Press.

Peacocke, C. 1992. Scenarios, concepts, and perception. In T. Crane, ed. The Contents of Experience. Cambridge: Cambridge University Press.

Peacocke, C. 1999. Being Known, Oxford: Clarendon Press.

Perry, J. 1979. The problem of the essential indexical. Noûs, 13(1), pp.3-21.

Romdenh-Romluc, K. 2011. Merleau-Ponty and Phenomenology of Perception, London: Routledge.

Schellenberg, S. 2007. Action and self-location in perception. Mind, 116(463), pp.603-631.

Sekiyama, K. et al. 1996. Body image as a visuomotor transformation device revealed in adaptation to reversed vision. Ecol. Monogr, 66, pp.301-321.

Smith, J. 2005. "Merleau-Ponty and the Phenomenological Reduction." Inquiry 48 (6): 553571.

- - . 2006. "Bodily Awareness, Imagination and the Self." European Journal of Philosophy 14 (1): 49-68. 
Stratton, G.M. 1896. Some preliminary experiments on vision without inversion of the retinal image. Psychological Review, 3(6), p.611.

Stratton, G.M. 1897. Vision without inversion of the retinal image. Psychological Review, 4(4), p.341.

Strawson, G. 1994. Mental Reality, Cambridge, MA: MIT Press.

Taylor, C. 1978. The validity of transcendental arguments. Proceedings of the Aristotelian Society, 79, pp.151-165. 